\title{
¿Qué (no) representan los diputados locales? Sistema electoral mexicano, actitudes y desconfianza
}

\author{
What do (not) local deputies represent? Mexican \\ electoral system, attitudes and distrust
}

\author{
doi: https://doi.org/ \\ 10.32870/eees.v27i77.7091
}

\author{
Mónica Montaño Reyes
}

\begin{abstract}
Resumen
Partiendo de la idea de que los sistemas electorales representan la conjunción entre los principios teóricos de la democracia y su materialización en la representación política, este artículo propone un marco de análisis para valorar el nivel de representatividad en un recinto legislativo subnacional en México a partir de: I) la noción de representación en la que está basado en sistema electoral mexicano, 2) la misma noción en el representante y 3) la crisis de representatividad que padecen los diputados. Se presenta una caracterización del sistema electoral mexicano, tanto nacional como subnacional, con predominancia de la representación descriptiva en términos territoriales, y se muestran los casos de ocho entidades federativas con distinta cantidad de población representada. Se concluye que a pesar de que el sistema electoral mexicano está basado en una noción totalmente territorial, los diputados locales no la consideran como elemento principal para asegurar una mejor representación.
\end{abstract}

Palabras clave: sistema electoral, representación, Congresos locales, democracia, México.

\begin{abstract}
Starting from the idea that electoral systems represent the conjunction between the theoretical principles of democracy and its materialization in political representation, this article proposes an analysis framework to assess the level of representativeness in a subnational legislative congress in Mexico from : I) the notion of representation on which it is based on the Mexican electoral system, 2) the same notion on the representative, and 3 ) the crisis of representativeness suffered by the deputies. A characterization of the Mexican national and subnational electoral system is offered, with a predominance of the descriptive representation in territorial terms, and the cases of eight federative entities with different amount of population represented are shown. It is concluded that although the Mexican electoral system is based on a totally territorial notion, local deputies do not consider it as the main element to ensure a better representation.
\end{abstract}

Keywords: Electoral system, representation, local congresses, democracy, Mexico.

\footnotetext{
- Profesora-Investigadora del Departamento de Estudios Políticos de la Universidad de Guadalajara, México. ORCID: https://orcid.org/0000-0003-0953-988 I

monica.montano@csh.udg.mx

Fecha de recepción: 12 de marzo de 2019. Fecha de aceptación: 13 de mayo de 2019.
} 
Introducción

La democracia moderna no se puede entender sin el adjetivo representativo. Lo es, sobre todo, debido a la ampliación del número de personas que participan en las decisiones en nuestras sociedades modernas y complejas, desde el supuesto de que los ciudadanos no pueden ejercer de forma directa el poder soberano y seleccionan a un representante -en el caso de este trabajo, a un diputado- que tomará decisiones vinculantes en su nombre.

Para Vallés y Bosch (1997), esta distinción entre dos clases de ciudadanos, gobernantes y gobernados, es el costo de la democracia. En esta distinción, se plasma la asimetría entre dichas clases de ciudadanos -que son, por ende, representados y representantes-, y más aún, la diferencia en torno a qué se representa en ciertos arreglos institucionales, si a los individuos o a los grupos y, por tanto, qué es representado en mayor proporción.

La definición de representación, por tanto, se vincula a un modelo que habla de la representación de individuos y a un modelo que se vincula a la representación de causas o bloques sociales muy bien definidos. Tanto los antecedentes históricos del concepto como la figura de los diputados y el Parlamento se remontan a las primeras asambleas de la Edad Media; ambos se fortalecieron tras la Revolución inglesa de 1651, con la guerra de parlamentaristas contra monarquistas; después, en la Guerra de Independencia norteamericana, de 1776; y finalmente con la Revolución francesa, de 1789.

Estos escenarios fueron acompañados por pensadores y diputados que teorizaron sobre la función de la representación y el espacio parlamentario -como con la representación fiduciaria de Edmund Burke (Burke, 1942a y 1942b; Eulau, Wahlke, Buchanan, y Ferguson, 1959; Conniff, 1977; Cotta, 
¿Qué (no) representan los diputados locales? Sistema electoral mexicano, actitudes y desconfianza

2007) o la representación de delegado ${ }^{1}$ de James Madison (Morgan, 1974; Cotta, 2007), por ejemplo-, así como llevaron a cabo la discusión entre el mandato imperativo y el mandato representativo (Pitkin, 1985; Sartori, 1988; Cotta, 2007; Brito Vieira y Runciman, 2008; Rehfeld, 2018). Fue hasta el siglo xx cuando devino una conceptualización en armonía con las teorías de la democracia moderna (Sartori, 1988).

La representación puede entenderse como una relación entre la voluntad de los electores y la de su diputado, así como la capacidad de que este sea sancionado por sus acciones (Pasquino, 2011, p. 215). Entendido así, el Parlamento como órgano representativo, imbricado en la dinámica de las democracias modernas, mantiene como un requerimiento esencial contar con mecanismos que permitan interpretar la noción de la representatividad y, sobre todo, reflejarla en entornos de toma de decisiones.

Los sistemas electorales que regulan la elección de los diputados por voto directo ${ }^{2}$ representan la conjunción entre los principios de la democracia en sus aspectos teóricos y la materialización de la representación política. Pueden definirse como fórmulas que permiten que los votos que los ciudadanos emiten en un proceso electoral imparcial se conviertan en espacios de decisión política o curules, sillas en el Congreso o Parlamento, entendidos como espacios de poder.

A pesar de la pertinencia y actualidad de estos conceptos, en México y América Latina hay pocos estudios tanto empí-

I. El debate entre las nociones de representación fiduciaria y delegativa (Cotta, 2007) cobra mucho sentido al momento de analizar a los diputados locales y la crisis de representatividad (Joignant, Morales, y Fuentes, 2017), pues mientras la primera reconoce la autonomía del actor político, la segunda lo concibe como simple ejecutor de los deseos de sus votantes. En ambos sentidos se han nutrido las líneas de investigación sobre desconfianza hacia los Congresos y diputados, pues parten de premisas opuestas: la primera en términos del modelo del elitismo democrático (Körösényi, 2009) de autorización representado, y la segunda del modelo de mandato.

2. Este estudio se enfoca solamente en los diputados electos por voto directo o mayoría relativa, por lo que la reflexión sobre los diputados de representación proporcional no es objeto del mismo. 
ricos como conceptuales que muestren los dilemas y dificultades en torno a la relación representante-representado, así como los elementos institucionales que le son inherentes, y todavía se ha abordado muy poco a nivel subnacional (Montaño y Patrón, 2017). En otros contextos, sobresalen los estudios sobre Inglaterra (Rehfeld, 2005), Norteamérica (Miller y Stokes, 1963) y algunos Congresos de América Latina (Stokes, 1998). En estos se ha hecho énfasis en la relación que guarda el diputado con sus propias creencias, con su partido político y el distrito que representa.

Así pues, el objetivo de este artículo es contribuir a estas propuestas teóricas y empíricas a través de un marco de análisis para valorar el nivel de representatividad en un recinto legislativo. Las dimensiones con las que se aborda son: 1) la noción de representación en la que está basado el sistema electoral del Poder Legislativo, 2) la noción de representación o actitud política en la que basa su actividad el diputado, y 3) la percepción de representación de los ciudadanos hacia los diputados y de los diputados hacia el Congreso local. En la Tabla 1, se muestran las variables a analizar, su medición y las fuentes utilizadas para el desarrollo de esta investigación.

Tabla 1. Operacionalización de variables y fuentes de información

\begin{tabular}{lll}
\multicolumn{1}{c}{ Variable } & \multicolumn{1}{c}{ Operacionalización } & \multicolumn{1}{c}{ Fuentes } \\
\hline Noción de & Criterios que favorece el & Constituciones \\
representación & sistema electoral (Reynolds, & mexicanas (1814, \\
en el sistema & Reilly, y Ellis, 2005) en torno & 1824, 1857, 1917). \\
electoral & a la representatividad de & Criterios de \\
legislativo & un diputado en términos & redistritación del \\
& de representación formal, & Instituto Nacional \\
& simbólica, espejo o sustantiva & Electoral (INE) de 2015. \\
& (Pitkin, 1985). & \\
\hline
\end{tabular}


¿Qué (no) representan los diputados locales? Sistema electoral mexicano, actitudes y desconfianza

\begin{tabular}{lll}
\multicolumn{1}{c}{ Variable } & \multicolumn{1}{c}{ Operacionalización } & \multicolumn{1}{c}{ Fuentes } \\
\hline Noción de & Creencias o actitudes & Encuesta Élites \\
en los diputados & (Almond y Verba, 1963) & Parlamentarias \\
locales & de los actores políticos en & Locales en México (de \\
& términos de representación & 2013 a 2015). \\
& fiduciaria, de delegado, espejo & \\
& o sociológica y sustantiva & \\
& (Pitkin, 1985; Cotta, 2007), & \\
& en torno a su actividad como & \\
& diputados. Se utilizan las & \\
& preguntas: \\
& 1. ¿A quién cree usted que \\
& representa durante su & \\
& actividad parlamentaria? \\
& 2. ¿Cuál de las siguientes \\
& características considera & \\
& usted que asegura una mejor \\
& representación? \\
& 3. Desde su función \\
& legislativa, ¿actúa de acuerdo \\
& a lo que sus votantes le piden \\
& o según lo que usted cree que \\
& es mejor para ellos? \\
& 4. Entre los siguientes \\
grupos, personas o & \\
instituciones, ¿a quién tiene & \\
& más en cuenta cuando toma & \\
& decisiones políticas en primer & \\
& lugar? & \\
& \\
\hline
\end{tabular}




\begin{tabular}{|c|c|c|}
\hline Variable & Operacionalización & Fuentes \\
\hline $\begin{array}{l}\text { Percepción de } \\
\text { representación } \\
\text { del Poder } \\
\text { Legislativo por } \\
\text { parte de los } \\
\text { ciudadanos }\end{array}$ & $\begin{array}{l}\text { Confianza entendida como } \\
\text { evaluación de los ciudadanos } \\
\text { hacia las expectativas } \\
\text { generadas por los diputados } \\
\text { (Almond y Verba, 1963; } \\
\text { Montero, Zmerli, y Newton, } \\
\text { 2008; Enriquez, 2010). Se } \\
\text { utiliza la pregunta: } \\
\text { ¿Qué nivel de confianza le } \\
\text { merecen los diputados? } \\
\text { 1. Nada. } \\
\text { 2. Poco. } \\
\text { 3. Algo. } \\
\text { 4. Mucha. }\end{array}$ & $\begin{array}{l}\text { Encuesta Informe País } \\
\text { de la Calidad de la } \\
\text { Ciudadanía (de } 2013 \\
\text { a 2015). }\end{array}$ \\
\hline $\begin{array}{l}\text { Percepción de } \\
\text { representación } \\
\text { del Poder } \\
\text { Legislativo por } \\
\text { parte de los } \\
\text { diputados }\end{array}$ & $\begin{array}{l}\text { Confianza entendida } \\
\text { como evaluación de los } \\
\text { actores políticos hacia las } \\
\text { instituciones representativas } \\
\text { (Montero, Zmerli, y Newton, } \\
\text { 2008; Rivas y Alcántara, } \\
\text { 2019). } \\
\text { ¿Qué nivel de confianza le } \\
\text { merece su Congreso local? } \\
\text { 1. Nada. } \\
\text { 2. Poco. } \\
\text { 3. Algo. } \\
\text { 4. Mucha. }\end{array}$ & $\begin{array}{l}\text { Encuesta Élites } \\
\text { Parlamentarias } \\
\text { Locales en México (de } \\
2013 \text { a 2015). }\end{array}$ \\
\hline
\end{tabular}

Fuente: elaboración propia

En la primera parte del artículo, se hace un análisis de la noción de representación en la legislación electoral según la redacción de artículos constitucionales respecto al Poder Legislativo nacional y subnacional. Después, se muestra la noción de representación a partir de las respuestas de los diputados locales a la encuesta Élites Parlamentarias Locales en México (de 2013), coordinada por el Observatorio Político Electoral de la Universidad de Guadalajara 
¿Qué (no) representan los diputados locales? Sistema electoral mexicano, actitudes y desconfianza

en nueve entidades federativas de México. ${ }^{3}$ Finalmente, se muestra una comparación entre la percepción de representación o confianza sobre los diputados (reflejada en Instituto Nacional Electoral y El Colegio de México -2015-) y la confianza de los mismos diputados hacia su Congreso. ${ }^{4}$

\section{Representar según la ley: ¿a quién} representan los diputados electos?

En este apartado, se muestra evidencia de que el diseño del sistema electoral mexicano para la representación legislativa ha sido formulado con base en criterios territoriales, y por ende, que los diputados electos por voto directo representan territorios y población. Es decir, se podrá observar cómo la elección de los diputados de mayoría relativa se ha moldeado acorde al concepto de representación descriptiva.

En ese sentido, y siguiendo a Pitkin (1985), la representación descriptiva implica "una correspondencia o semejanza precisas con respecto de aquello que representa, mediante un reflejo no distorsionado" (p. 65). Esta podría entenderse como la base del sistema electoral en México, incluso a pesar de que Pitkin y otros autores no especifican "qué es lo que hay que reflejar en el órgano representativo de la realidad social" (Laporta, s/f, p. 133).

Partiendo de esta conceptualización, se esperaría que la elección sirviera para la selección del representante que más se pareciera a la comunidad representada, cuya unidad básica es el distrito o circunscripción, esto es, el "conjunto

3. La encuesta fue aplicada a ciento cincuenta y seis diputados locales de nueve estados de la república en el periodo 2013-20I5. La ficha técnica del estudio, el cuestionario, así como las bases de datos pueden encontrarse en Observatorio Político Electoral (20/3).

4. La percepción de representación o confianza se toma de los resultados de la encuesta Informe País de la Calidad de la Ciudadanía, levantada en 20 I 3 a I I 000 ciudadanos mexicanos de todas las entidades federativas, y publicada en 2015 (Instituto Nacional Electoral y El Colegio de México, 20 I5). 
de electores agrupados generalmente sobre una base territorial, a partir de cuyos votos se procede a la distribución entre candidatos de los escaños" (Vallés y Bosch, 1997, p. 76). Así pues, es necesario mostrar cómo la noción que prevalece en el sistema electoral mexicano de la representación política, tanto a nivel nacional como subnacional, es sobre todo territorial.

En términos prácticos, el estudio de la representación de un grupo es resultado de un cálculo especial sobre los agregados de individuos, por lo cual es necesario entender cómo se originan estas fórmulas o arreglos institucionales que generan nuestros Congresos o Parlamentos, los llamados sistemas electorales.

Los sistemas electorales son la forma básica mediante la cual se expresa la democracia moderna, además de que "son construcciones procedimentales destinadas a constituir la representación en la forma deseada" (De Grazia, 1977, p. 303). Un sistema electoral es un mecanismo por medio del cual los votos emitidos por los ciudadanos se traducen en espacios de poder político y de toma de decisiones, y, en el caso de estudio de este artículo, de curules legislativas. Los sistemas electorales forman parte crucial del juego democrático pues son el conjunto de leyes y normas que rigen la competencia electoral entre los actores y los partidos y definen quién ocupará los espacios de poder (Cox, 2004, p. 58).

Entonces, para hablar de la noción de representación que predomina en el sistema electoral mexicano para la elección de los diputados nacionales y subnacionales, se hace una revisión histórica de la legislación nacional, que es de donde emanan después las legislaciones subnacionales o estatales.

I. I Representar almas y habitantes:

los diputados nacionales entre 1824 y 1977

En México, después de la independencia, se dieron los primeros intentos por reorganizar la vida política del país. 
¿Qué (no) representan los diputados locales? Sistema electoral mexicano, actitudes y desconfianza

Destaca en ese sentido el Reglamento Provisional Político del Imperio Mexicano, promulgado en 1822 por la Junta Nacional Instituyente del Imperio de Iturbide (1822), que, sin embargo, no abordó de forma clara la representación de los diputados electos ni las equivalencias poblacionales o territoriales que debían existir para la elección de los mismos.

Cuando terminó la monarquía de Iturbide y se transitó hacia la primera república, se presentó la principal transformación en materia de representación política, amparada en la constitución de 1824, que en su artículo 10 declaraba que "la base general para el nombramiento de diputados será la población", en ese tiempo entendida en un número limitado de almas (ver: Tabla 2). En 1824, las entidades federativas tenían una representación política mediada por la Cámara de Senadores, por lo que era necesaria una representación adicional, lograda a través de la Cámara de Diputados. Así, el enfoque de representación vinculado con la población marcó una tendencia dentro de la tradición constitucionalista mexicana a partir de entonces.

En la constitución de 1857, dicha tendencia se mantuvo. Esta carta magna consideró a la población como un referente para la integración de la representación política, aunque sólo a nivel nacional y no subnacional, pues se sobreentendía que la intención del Congreso constituyente era que por medio de la legislación nacional se establecieran parámetros para esa otra integración regional. Sería hasta la constitución de 1917 cuando se buscaría establecer de forma más clara la integración del Poder Legislativo y la relación de representación, al especificar en su artículo 52 que "se elegirá un diputado propietario por cada sesenta mil habitantes o por una fracción que pase de veinte mil, teniendo en cuenta el censo general del Distrito Federal y el de cada estado y territorio".

Posteriormente, como resultado de la reforma político-electoral impulsada por el entonces presidente José 
López Portillo en 1977, el artículo 52 constitucional sufrió una modificación. La reforma de López Portillo contenía elementos característicos que revelan una transformación de fondo en el entendimiento de la representación política, ahora encarnada en los diputados, y dividió a la población en trescientos territorios (o distritos electorales), lo que entendió de manera distinta la representación territorial: de una tendencia generalmente vinculada a cantidades precisas de población, la reforma de 1977 la comprendió como una relación entre el diputado y su integración a una dualidad territorio-población, mantenida esta última como un eje preponderante sobre la población.

Tras dicha reforma, aunque no se podría hablar de una absoluta ausencia del elemento de integración territorial, sí se puede decir que existe una complejidad mayor al entender la relación directa entre población y territorio en el sistema electoral mexicano. Al eliminar la relación directa entre número absoluto de población por escaño legislativo, se modificó de forma sustantiva la naturaleza del propio sistema electoral. Actualmente, la relación entre diputado y ciudadano se encuentra mediada por esta entidad territorial (el distrito), que es retomada en el siguiente apartado.

Tabla 2. Disposiciones de representación poblacional legislativa a nivel nacional

\begin{tabular}{lll}
\multicolumn{1}{c}{ Ordenamiento } & \multicolumn{1}{c}{$\begin{array}{c}\text { Tasa de representación } \\
\text { (un representante por cada...) }\end{array}$} & \multicolumn{1}{c}{$\begin{array}{c}\text { Fundamento } \\
\text { legal }\end{array}$} \\
\hline $\begin{array}{l}\text { Decreto Constitucional } \\
\text { para la Libertad de } \\
\text { la América Mexicana, }\end{array}$ & $\begin{array}{l}\text { La soberanía reside originariamente en el } \\
\text { pueblo, y su ejercicio en la representación } \\
\text { nacional compuesta de diputados elegidos por } \\
\text { o Constitución de }\end{array}$ & los ciudadanos \\
$\begin{array}{l}\text { Apatzingán (1814) } \\
\text { Constitución de 1824 }\end{array}$ & $\begin{array}{l}80 \text { 000 almas } \\
\text { Por cada fracción que pase de } \\
\end{array}$ & Artículo 11 \\
& 4000 almas & \\
\hline
\end{tabular}


¿Qué (no) representan los diputados locales? Sistema electoral mexicano, actitudes y desconfianza

\begin{tabular}{|c|c|c|}
\hline Ordenamiento & $\begin{array}{c}\text { Tasa de representación } \\
\text { (un representante por cada...) }\end{array}$ & $\begin{array}{c}\text { Fundamento } \\
\text { legal }\end{array}$ \\
\hline Constitución de 1857 & $\begin{array}{l}40000 \text { almas } \\
\text { Por cada fracción que pase de } \\
20000 \text { almas }\end{array}$ & Artículo 53 \\
\hline Constitución de 1917 & $\begin{array}{l}60000 \text { habitantes } \\
\text { Por cada fracción que pase de } \\
20000 \text { habitantes }\end{array}$ & Artículo 52 \\
\hline $\begin{array}{l}\text { Constitución de } 1917 \\
\text { (Reforma } 20 \text { de agosto } \\
\text { de 1928) }\end{array}$ & $\begin{array}{l}100000 \text { habitantes } \\
\text { Por cada fracción que pase de } \\
50000 \text { habitantes }\end{array}$ & \\
\hline Constitución de 1917 & 150000 habitantes & \\
\hline $\begin{array}{l}\text { (Reforma } 20 \text { de agosto } \\
\text { de 1942) }\end{array}$ & $\begin{array}{l}\text { Por cada fracción que pase de } \\
75000 \text { habitantes }\end{array}$ & \\
\hline Constitución de 1917 & 170000 habitantes & \\
\hline $\begin{array}{l}\text { (Reforma } 11 \text { de junio de } \\
1951 \text { ) }\end{array}$ & $\begin{array}{l}\text { Por cada fracción que pase de } \\
80000 \text { habitantes }\end{array}$ & \\
\hline Constitución de 1917 & 200000 habitantes & \\
\hline (Reforma 20 de & Por cada fracción que pase de & \\
\hline diciembre de 1960) & 100000 habitantes & \\
\hline Constitución de 1917 & 250000 habitantes & \\
\hline $\begin{array}{l}\text { (Reforma } 8 \text { de octubre } \\
\text { de 1974) }\end{array}$ & $\begin{array}{l}\text { Por cada fracción que pase de } \\
125000 \text { habitantes }\end{array}$ & \\
\hline $\begin{array}{l}\text { Constitución de } 1917 \\
\text { (Reforma } 6 \text { de diciembre } \\
\text { de 1977) }\end{array}$ & $\begin{array}{l}\text { Población total del país entre } \\
\text { trescientos diputados electos en } \\
\text { distritos uninominales }\end{array}$ & Artículo 53 \\
\hline
\end{tabular}

Fuentes: elaboración propia con base en los ordenamientos señalados.

Por otro lado, ya desde 1965 se había introducido otra figura de representación en la integración de los Congresos: los diputados que representan partidos políticos. Entre 1977 y 1986, los diputados federales de representación proporcional aumentaron a la suma de doscientos, vigente hasta hoy. Este estudio, sin embargo, se enfoca en el análisis sobre los diputados por elección directa en distritos uninominales. ${ }^{5}$

5. Sobre la representación de partidos políticos en Congresos locales, puede profundizarse en: Macedonio y Montaño (20l8).

Estado $\&$ No.77 


\section{2 Los diputados y Congresos locales en la legislación federal entre 1824 y 1977}

A la par de la concepción del diputado nacional, en la legislación federal mexicana también se han ido sentando las bases para comprender a su equivalente subnacional. Ahora bien, en cuanto a lo que representan los diputados locales y cómo se conforman los Congresos de los estados, hay muy escasa información en las constituciones de 1824 y 1857. Fue hasta la constitución de 1917 que se establecieron criterios mínimos para la integración de los Poderes Legislativos locales, dando por sentado que estos criterios generales deben guiar la forma en que se construyen las leyes particulares al respecto.

La constitución de 1917 confirmó una previsión clara: la base fundamental de la representación de los diputados locales también es la población. Su artículo 115 estableció que "el número de representantes en las legislaturas de los estados será proporcional al de habitantes de cada uno, en todo caso, el número de representantes de una legislatura local no podrá ser menor de quince diputados".

De este modo, a partir de dicho artículo, se ha impuesto la necesidad de proporcionalidad entre población y representación política de los diputados, y se estableció un número mínimo de integrantes de las legislaturas estatales. Con todo esto, queda claro el espíritu y la vinculación de la representación poblacional en la tradición constitucional mexicana, y sobre todo en la actual carta magna, aunque dicha fórmula ha sufrido diversos cambios a lo largo del tiempo.

También, la evolución de las disposiciones constitucionales en torno a la integración de los Congresos estatales mantiene paralelismos claros con la de las que rigen la integración de la Cámara de Diputados, lo que se entiende como una tendencia clara de influenciar y determinar -por derivación- algunos mecanismos de integración de los 
¿Qué (no) representan los diputados locales? Sistema electoral mexicano, actitudes y desconfianza

Poderes Legislativos estatales con base en la integración del Poder Legislativo nacional.

La reforma constitucional de 1928 eliminó la exigencia de que la legislatura estatal no tuviera menos de quince diputados, pero a la vez estableció rangos de población y mínimos de escaños de representantes, como lo hizo para los diputados nacionales. Los rangos mínimos (establecidos por la fórmula "no tendrá menos de") marcan un límite a la subrrepresentación, pero no para la sobrerrepresentación, ya que el rango máximo no se especifica en ningún punto de la constitución. Este se mantuvo, entonces, como una prerrogativa de las propias entidades federativas, para que en uso de su autonomía pudieran establecer los límites y las equivalencias poblacionales, aunque atendiendo principios generales emitidos por el Congreso constituyente.

Se puede apreciar nuevamente que en el fondo de la narrativa de los artículos modificados en 1928 (52 para la ordenanza del Congreso federal; 115 para la ordenanza de los Congresos estatales) subyace un intento por establecer criterios similares para todas las entidades federativas, entendiendo que si bien estas mantienen esferas de autonomía bien determinadas no pueden transgredir, en el uso de sus libertades, ciertos elementos de integración básica que buscan no sólo uniformar los poderes de los estados, sino también darle coherencia y sentido a la unidad federal.

Ahora bien, a pesar de que el artículo 115 constitucional se modificó a lo largo del siglo xx, no sufrió cambios sobre la integración de los Congresos en las entidades y conserva los números redactados en la reforma de $1928^{6}$ (Tabla 3).

6. Sólo en 1977 sufrió los efectos de la reforma sobre los diputados de representación proporcional. 
Tabla 3. Disposiciones de representación poblacional legislativa a nivel local

\begin{tabular}{lll}
\multicolumn{1}{c}{ Ordenamiento } & \multicolumn{1}{c}{ Tasa de representación } & \multicolumn{1}{c}{$\begin{array}{c}\text { Fundamento } \\
\text { legal }\end{array}$} \\
\hline $\begin{array}{l}\text { Constitución de } \\
1917\end{array}$ & $\begin{array}{l}\text { No podrán ser menos de quince } \\
\text { diputados locales por Congreso }\end{array}$ & Artículo 115 \\
Constitución de & No menos de siete diputados en & Artículo 115 \\
1917 & estados con menos de 400 000 & (116 actual) \\
(Reforma del & habitantes. \\
20 de agosto de & No menos de nueve diputados en & \\
$1928)$ & estados con más de 400 000 pero & \\
& menos de 800 000 habitantes. & \\
& Once diputados cuando el estado & \\
& tenga más de 800 000 habitantes. & \\
\hline
\end{tabular}

Fuente: elaboración propia con datos de las regulaciones mencionadas.

\section{3 La representación del distrito: territorio} homogéneo y población desigual

Como se anticipó, a partir de la reforma constitucional de 1977, el nuevo vocablo para referir a la unidad y célula básica de la representación del diputado de mayoría relativa es el distrito electoral. Vallés y Bosch (1997, p. 76) definen distrito o circunscripción como el conjunto de electores agrupados en la base territorial a partir de cuyos votos se procede a la distribución, entre candidatos contendientes, de los escaños que constituyen el órgano legislativo.

Con la reforma electoral de 2016 al artículo 53 constitucional, se indicó la manera en que se debían determinar los distritos, pero dicha modificación no intentó plantear el concepto mismo ni su naturaleza representativa, además de que la redacción final del artículo reconoció entre las facultades del Instituto Nacional Electoral (INE) la determinación de la geografía electoral. En la guía de distritación realizada por el mismo instituto en 2015 (Instituto Nacional Electoral, 2015), se hizo énfasis en dos criterios para la base 
¿Qué (no) representan los diputados locales? Sistema electoral mexicano, actitudes y desconfianza

del sistema electoral mexicano: el equilibrio poblacional y la forma del territorio de los distritos.

En términos de distritos electorales federales, el Sistema de Información Legislativa (SIL) los define como la división geográfica en que se organiza el territorio con fines electorales. Para sufragar, todos los electores se ubican conforme a su domicilio en dicho territorio, que a su vez se divide en secciones correspondientes a las casillas donde los electores depositarán su voto durante la elección. La demarcación de los distritos resulta de dividir la población total del país (conforme al último censo) entre los trescientos distritos federales (Sistema de Información Legislativa, 2017). En este sentido, la distritación que se aplicó a partir de 2017 en el país buscaba tener mayor equilibrio poblacional entre los trescientos distritos electorales.

Para el caso de los distritos electorales estatales, se buscó en cada una de las treinta y una legislaciones locales su definición de distrito electoral. Sin embargo, hasta el 2017, sólo tres estados incluían una definición como tal (Tabla 4).

Tabla 4. Concepto de distrito electoral en las entidades que lo contemplan en sus legislaciones particulares

\begin{tabular}{cll} 
Entidad & \multicolumn{1}{c}{ Concepto } & \multicolumn{1}{c}{ Fuente } \\
\hline Colima & Se entiende por distrito electoral & Artículo 20 del \\
& uninominal la demarcación territorial & Código Electoral \\
& donde se elegirá a un diputado por el & del Estado de \\
& principio de mayoría relativa & Colima \\
Jalisco & Distrito electoral uninominal es la & Artículo 219 del \\
& demarcación geográfica electoral dentro & Código Electoral \\
& de la cual se vota para elegir a los & y de Participación \\
& diputados por el principio de mayoría & Social del Estado \\
& relativa & de Jalisco \\
\hline
\end{tabular}

Estado 8 No.77 


\begin{tabular}{lll}
\multicolumn{1}{c}{ Entidad } & \multicolumn{1}{c}{ Concepto } & \multicolumn{1}{c}{ Fuente } \\
\hline Nuevo & Para la elección de los diputados de & Artículo 179 de \\
León & mayoría relativa, el territorio del & la Ley Electoral \\
& estado se dividirá en veintiséis distritos & para el Estado de \\
& uninominales, los cuales tendrán unidad & Nuevo León \\
& geográfica por ser porciones naturales & \\
& y continuas de territorio, [y] agruparán & \\
& varios municipios pequeños completos o & \\
& una sola porción de un municipio grande
\end{tabular}

Fuente: elaboración propia con base en la legislación electoral de los estados, revisada hasta el 1 de noviembre de 2017.

Además, al calcular el número promedio real de habitantes representados por los diputados locales de mayoría relativa, se descubre que los distritos electorales locales se encuentran en casos extremos de desigualdad de población. El número de población representada se puede dividir en cuatro rangos (Tabla 5). Los estados cuyos diputados locales representan a mayor cantidad de población son Jalisco y el Estado de México, con promedios que superan los 300000 habitantes por diputado local. Les siguen Veracruz, Guanajuato y Puebla, con promedios que superan los 200000 habitantes por diputado local.

Por otra parte, en el otro extremo de la representación están estados como Baja California Sur y Campeche, que mantienen un promedio de representación poblacional de cerca de 40000 habitantes por diputado local. Si se comparan los casos extremos, se encuentra que un diputado local de Campeche-que en teoría debe tener la misma condición que cualquier otro diputado local del país- representa apenas a un $10 \%$ de la población que representa un diputado del estado de Jalisco. 
¿Qué (no) representan los diputados locales? Sistema electoral mexicano, actitudes y desconfianza

Tabla 5. Población promedio representada por diputado local en México

\begin{tabular}{|c|c|c|c|c|}
\hline Lugar & $\begin{array}{c}\text { Rango } 1 \\
\text { De } 39164 \text { a } \\
92690 \\
\text { habitantes }\end{array}$ & $\begin{array}{c}\text { Rango } 2 \\
\text { De } 92691 \\
\text { a } 146217 \\
\text { habitantes }\end{array}$ & $\begin{array}{c}\text { Rango } 3 \\
\text { De } 146218 \\
\text { a } 256534 \\
\text { habitantes }\end{array}$ & $\begin{array}{c}\text { Rango } 4 \\
\text { De } 256535 \\
\text { a } 367534 \\
\text { habitantes }\end{array}$ \\
\hline 1 & Campeche & Morelos & Hidalgo & $\begin{array}{l}\text { Estado de } \\
\text { México }\end{array}$ \\
\hline 2 & $\begin{array}{c}\text { Baja California } \\
\text { Sur }\end{array}$ & Tabasco & Tamaulipas & Jalisco \\
\hline 3 & Colima & Durango & Oaxaca & \\
\hline 4 & Nayarit & Sinaloa & Chihuahua & \\
\hline 5 & Tlaxcala & Guerrero & Coahuila & \\
\hline 6 & Aguascalientes & Querétaro & $\begin{array}{l}\text { San Luis } \\
\text { Potosí }\end{array}$ & \\
\hline 7 & Zacatecas & Sonora & Nuevo León & \\
\hline 8 & Quintana Roo & Yucatán & Michoacán & \\
\hline 9 & & & $\begin{array}{c}\text { Baja } \\
\text { California }\end{array}$ & \\
\hline 10 & & & Chiapas & \\
\hline 11 & & & Puebla & \\
\hline 12 & & & Guanajuato & \\
\hline 13 & & & Veracruz & \\
\hline
\end{tabular}

La población promedio representada por diputado local resulta de dividir el número de población del estado entre el número de diputados locales que tiene cada Congreso estatal.

Fuente: elaboración propia con base en Instituto Nacional de Estadística y Geografía (2016) y en información de organismos públicos electorales de los estados (OPLES). ${ }^{7}$

Ahora bien, se ha realizado el mismo cálculo pero comparando la población que representa un diputado local y la que representa un diputado federal de la misma entidad federativa (Figura 1). Por las razones antes mencionadas

7. Aunque los datos de esta investigación se obtuvieron de los sitios de los treinta y un OPLES, la información puede ser encontrada de manera sintética en Instituto Mexicano para la Competitividad (2017). 
vinculadas con la legislación electoral, existe una mayor proporcionalidad entre los diputados federales de las entidades que entre los mismos en sus Congresos locales. Aun así, sorprende de nuevo la gran disparidad entre los estados del rango 1 y los del rango 4 .

Figura 1. Comparación de población representada por diputado local y federal según la entidad federativa (datos al 2016)

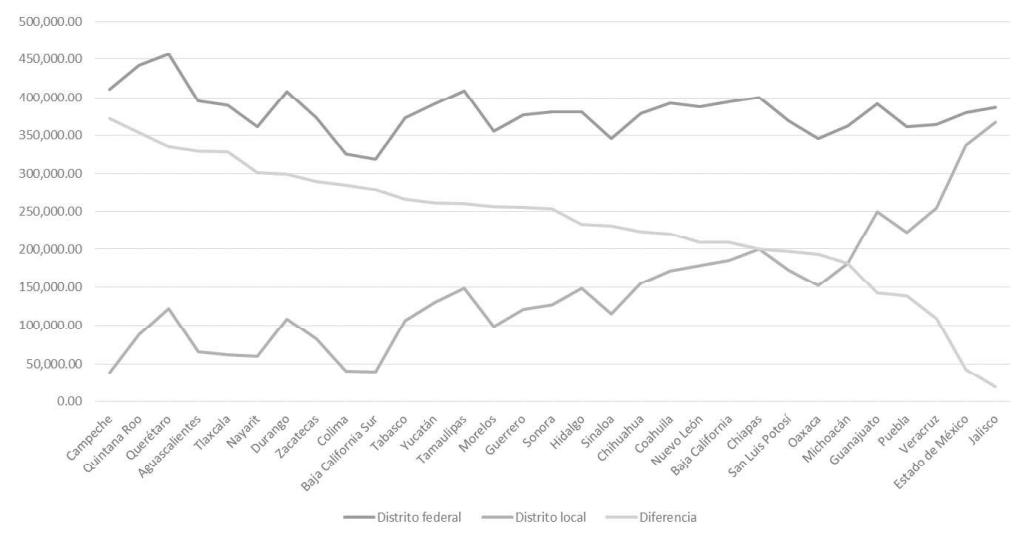

Fuente: elaboración propia con base en Instituto Nacional de Estadística y Geografía (2016) y en información de los OPLES correspondientes.

Desde este análisis, se ha querido comprobar que el sistema electoral federal y local fue construido en México bajo la lógica territorial, la más cercana a la representación descriptiva o espejo propuesta por Pitkin (1985). Es decir, los órganos representativos del país se modelaron desde una lógica aritmética que responde a cierta cantidad de población agrupada en un territorio determinado, llamado distrito. Así, la noción de representación que está detrás del diseño del sistema electoral mexicano es totalmente territorial y poblacional, pero ¿qué implicaciones tiene esto?

Sin duda, la representación territorial y la de partidos políticos son las dos nociones que por excelencia guían los 
¿Qué (no) representan los diputados locales? Sistema electoral mexicano, actitudes y desconfianza

sistemas electorales del mundo. En el caso de México, a nivel subnacional, se puede observar que la discusión al respecto toma relevancia sobre todo por los recientes cambios de la política local, donde hasta antes de la elección 2018 había un crecimiento de Gobiernos divididos (Lujambio, 1996), es decir, gobernadores sin mayoría absoluta de su partido en sus Congresos. Las implicaciones del diseño del sistema electoral en cuanto a la designación de los representantes en los Congresos locales mexicanos en términos territoriales ahora representan un reto en torno a qué tanto dicho diseño funciona para lograr la representación política.

$\mathrm{Al}$ menos hasta el año de realización del presente estudio, no existían aún otros mecanismos institucionales que ligaran de mejor manera al representante con su población y su territorio, como podrían hacerlo la reelección o la selección de candidatos para los distritos electorales (Tabla 6). La representación territorial ha sido hasta ahora un requisito a considerar para ser electo como diputado, pero genera poca atención en torno a la interacción representante-representado una vez que se ocupan las curules. A estas problemáticas hay que sumar las abismales diferencias en la cantidad de población representada por los diputados locales de mayoría relativa según la entidad federativa, ya revisadas anteriormente.

Tabla 6. Noción y mecanismos generales del diseño del sistema electoral subnacional

\begin{tabular}{ccc}
$\begin{array}{c}\text { Representación política que } \\
\text { favorecen }\end{array}$ & $\begin{array}{c}\text { Mecanismos } \\
\text { de selección de } \\
\text { candidatos }\end{array}$ & $\begin{array}{c}\text { Reelección } \\
\text { legislativa } \\
\text { inmediata }\end{array}$ \\
\hline $\begin{array}{c}\text { Descriptiva o de espejo a } \\
\text { través de la representación } \\
\text { territorial }\end{array}$ & $\begin{array}{c}\text { Dentro de las } \\
\text { instancias de los } \\
\text { partidos políticos }\end{array}$ & Prohibida \\
\hline
\end{tabular}

Fuente: elaboración propia con base en los ordenamientos electorales federales y estatales revisados en sus versiones actualizadas al 2016 .

Estado No.77 
A partir de estos hallazgos, del universo de treinta y una entidades federativas analizadas, se eligió una muestra de algunas entidades y diputados por cada uno de los cuatro rangos de población representada (Tabla 5) para analizar las nociones de representación de estos diputados locales.

\section{Noción de representación en diputados} locales: ¿qué y cómo creen representar?

El objetivo de este apartado es mostrar la noción de representación que predomina en diputados locales entrevistados. Es decir, se buscó analizar sus actitudes o creencias (Almond y Verba, 1963; Putnam, 1973), en términos de representación fiduciaria o de delegado (Cotta, 2007), espejo o sociológica, y sustantiva (Pitkin, 1985; Cotta, 2007), respecto de su actividad como diputados a partir de la aplicación de entrevistas cara a cara.

A partir del estudio del sistema electoral de las treinta y una entidades federativas, como ya se mencionó, se hizo una selección de casos de entidades que estuvieran en cada uno de los rangos de población marcados para el estudio, y se eligieron diputados con el fin de encontrar posibles diferencias o coincidencias en torno a su noción de representación política.

A partir de esta selección, se llevó a cabo el levantamiento de la encuesta Élites Parlamentarias Locales en México ${ }^{8}$ (Observatorio Político Electoral, 2013; Montaño y Patrón, 2017) a nivel subnacional en las siguientes entidades federativas:

8. Cabe recalcar que dicha encuesta fue el primer esfuerzo por entrevistar a los diputados locales del país, y se enfrentaron grandes problemas para cubrir una muestra representativa por entidad federativa, por ello, los resultados mostrados deben tomarse solamente como referencia. El total de levantamientos en cada entidad federativa fueron los siguientes:Aguascalientes $n=27$, Nayarit $n=15$, Sinaloa $n=33$, Guerrero $n=10$, Guanajuato $n=2 \mid$, Tamaulipas $n=\mid 5$, San Luis Potosí $n=13$, Estado de México $n=9$, Jalisco $n=13$. 
¿Qué (no) representan los diputados locales? Sistema electoral mexicano, actitudes y desconfianza

- Del rango 1 (de 39164 a 92690 habitantes): Aguascalientes ${ }^{9}$ y Nayarit ${ }^{10}$

- Del rango 2 (de 92691 a 146217 habitantes): Guerrero ${ }^{11}$ y Sinaloa ${ }^{12}$;

- Del rango 3 (de 146218 a 256534 habitantes): Guanajuato, ${ }^{13}$ San Luis Potosí1 ${ }^{14}$ y Tamaulipas ${ }^{15}$; y

- Del rango 4 (de 256535 a 367534 habitantes): Jalisco ${ }^{16}$ y Estado de México. ${ }^{17}$

\section{Figura 2. Población representada por diputado local según entidad federativa}

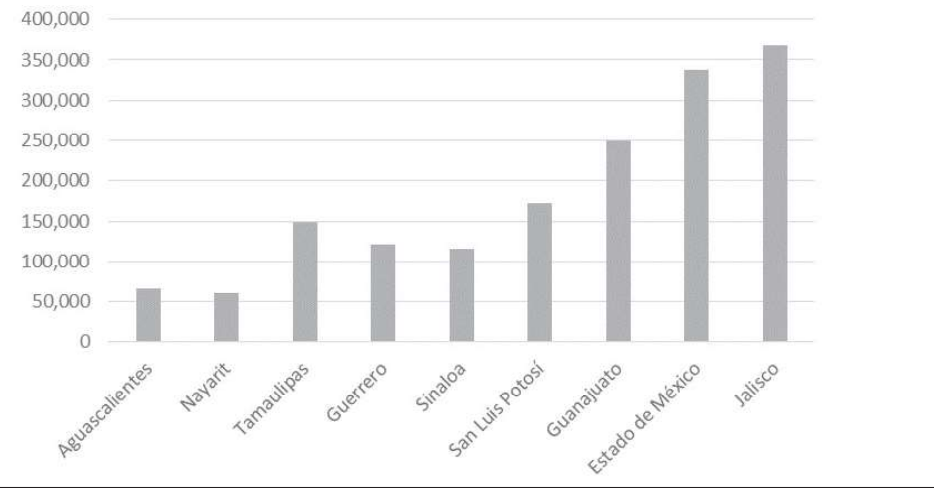

Fuente: elaboración propia con base en Instituto Nacional de Estadística y Geografía (2016) y en información de organismos públicos electorales de los estados.

9. Entrevistas y base de datos realizadas por Reyes (2017).

10. Entrevistas y base de datos realizadas por Azul Aguiar en Aguiar y Macedonio (2017).

II. Entrevistas y base de datos realizadas por Jiménez y Solano (20I7).

12. Debido a que se perdieron las bases de datos de esta encuesta, sólo se analizaron los datos agregados publicados en Solís, Cerna y Torre (20I7).

13. Entrevistas y base de datos realizadas por Oniel Díaz en Vázquez, Díaz y Hernández (2017).

14. Debido a que se perdieron las bases de datos de esta encuesta, sólo se analizaron los datos agregados publicados en Hernández (2017).

15. Entrevistas y base de datos realizadas por Casas (2017).

16. Entrevistas y base de datos realizadas por Mónica Montaño en Montaño y Patrón (2017).

17. Entrevistas y base de datos realizadas por Muñoz y Díaz (20I7). 
En la Figura 2, puede apreciarse que los casos seleccionados comprenden desde los diputados con menor cantidad de ciudadanos representados (como los de Nayarit) hasta los pertenecientes a estados con diputados locales con mayor cantidad de representados (como Jalisco).

El primer indicador para medir la noción de representación en los diputados locales de la encuesta mencionada fue la pregunta: "¿a quién cree usted que representa durante su actividad parlamentaria?". A pesar de que el sistema electoral mexicano está diseñado para que cada diputado represente al distrito por el que fue electo (esto en el caso de elección por mayoría relativa), la mayoría de los legisladores entrevistados dijo representar a toda su entidad federativa durante su actividad parlamentaria, es decir, si bien la encuesta se aplicó de manera muestral tanto a diputados de mayoría como de representación proporcional, ${ }^{18}$ la respuesta espontánea de los entrevistados se refirió a que representaban a todos los ciudadanos de su estado (Figura 3).

18. Cabe recalcar que la mayoría de los diputados locales entrevistados, aunque estos fueran electos por representación proporcional, refirió haber trabajado en un distrito o territorio específico desde los inicios de su carrera política, por lo que dichos diputados, a pesar de haber sido electos por estar integrados en listas, se sentían de alguna manera ligados a un territorio. 
¿Qué (no) representan los diputados locales? Sistema electoral mexicano, actitudes y desconfianza

Figura 3. ¿A quién cree usted que representa durante su actividad parlamentaria?

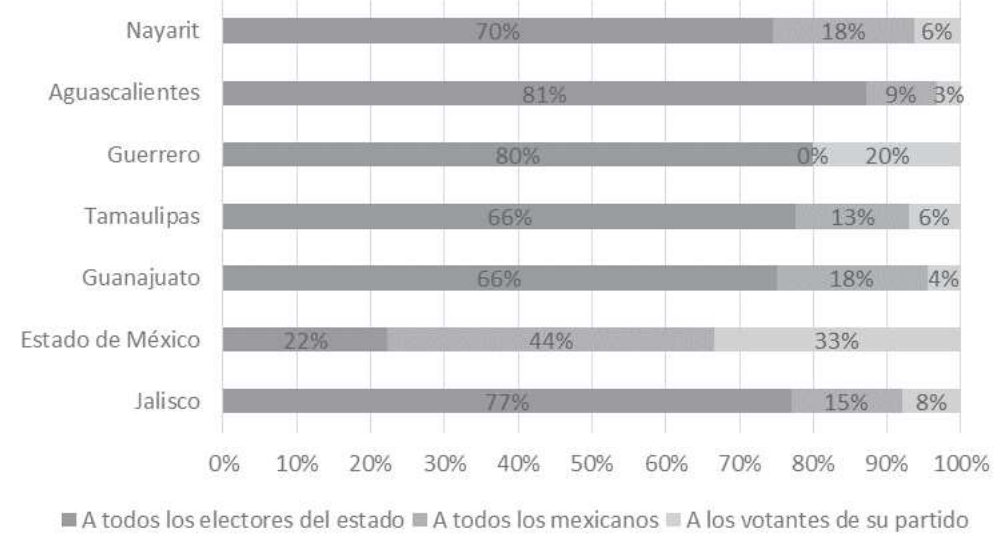

Número de casos: Aguascalientes $n=27$, Nayarit $n=15$, Guerrero $n=10$, Guanajuato $n=21$, Tamaulipas $n=15$, Estado de México $n=9$, Jalisco $\mathrm{n}=13$. Se excluyó a Sinaloa y San Luis Potosí porque no se contaba con los resultados de esta pregunta, pero se conservó otro estado de su mismo rango, como Guerrero del 2 y Guanajuato y Tamaulipas del 3.

Fuente: elaboración propia con base en Montaño y Patrón (2017).

En Guerrero y Aguascalientes, entidades de los rangos 2 y 1 , respectivamente, donde los diputados representan menor cantidad de habitantes por distrito local, se encontraron los porcentajes más altos ( $80 \%$ y $81 \%$, respectivamente) de diputados locales que dijeron creer representar a todos los electores de sus estados. A estos, les siguieron con 77\% los diputados de Jalisco, que representan a la mayor cantidad de ciudadanos por distrito local -rango 4-. Finalmente, Tamaulipas y Guanajuato, del rango 3, tuvieron $66 \%$ de diputados con la misma respuesta. El Estado de México resultó un caso interesante porque tuvo mayor sentido nacional: el 44\% de sus diputados respondió creer representar a todos los mexicanos. 
Por otro lado, el porcentaje de diputados que dijo representar a los votantes de su partido fue en general inferior al $10 \%$ en los estados de Nayarit, Aguascalientes, Tamaulipas, Guanajuato y Jalisco (de los rangos 1, 3 y 4). Por su parte, Guerrero y el Estado de México (de los rangos 2 y 4, respectivamente) fueron los estados donde la mayor parte de sus diputados locales refirió representar a los votantes de su partido (20\% y $33 \%$, respectivamente), independientemente de si eran diputados de mayoría relativa o de representación proporcional. Los entrevistados referían que al pertenecer a un partido político los ciudadanos habían votado por el programa político del mismo y, por lo tanto, sentían representar los principios políticos de quienes votaron por ellos.

En dichas respuestas se percibe una tendencia, en términos de Burke (Burke, 1942a y 1942b; Eulau et al., 1959; Conniff, 1977; Cotta, 2007), de que el diputado represente como fiduciario a la colectividad y no tanto a su lugar de proveniencia. Por lo tanto, en el ánimo general de los legisladores, la comunidad que sienten representar incluye a todos los habitantes del estado, por encima de la población de los distritos de donde fueron electos, o incluso de sus partidos políticos. 
¿Qué (no) representan los diputados locales? Sistema electoral mexicano, actitudes y desconfianza

Figura 4. ¿Cuál de las siguientes características considera usted que asegura una mejor representación?

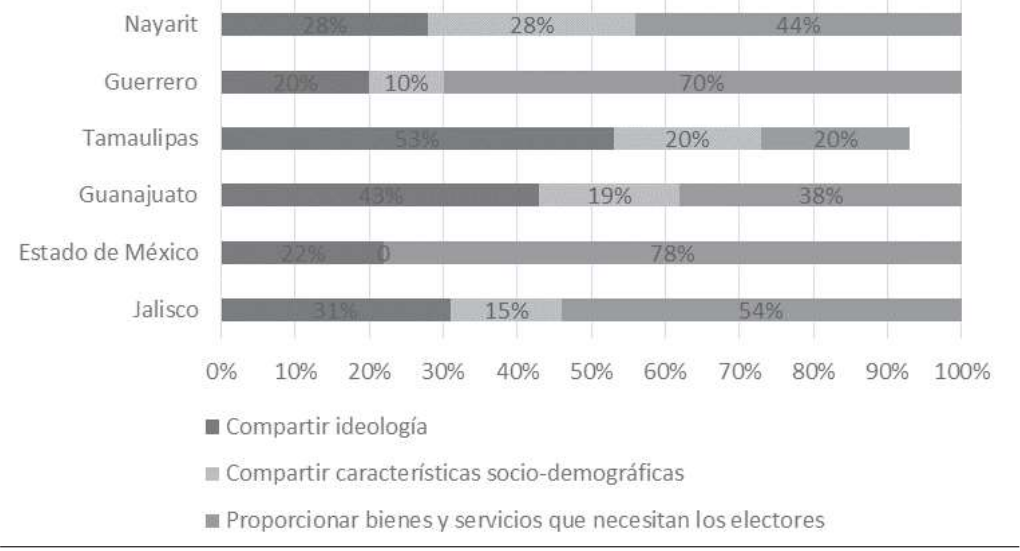

Número de casos: Nayarit $n=15$, Guerrero $n=10$, Guanajuato $n=21$, Tamaulipas n=15, Estado de México $\mathrm{n}=9$, Jalisco $\mathrm{n}=13$. Se excluyó a Aguascalientes, Sinaloa y San Luis Potosí porque no se contaba con sus resultados en esta pregunta, pero se conservó otro estado de su mismo rango, como Nayarit del 1, Guerrero del 2 y Guanajuato y Tamaulipas del 3.

Fuente: elaboración propia con base en Montaño y Patrón (2017).

Del mismo modo, en general, los diputados locales no creen que compartir características socio-demográficas (edad, género, etc.) asegure una mayor representación (Figura 4). En las entrevistas cara a cara con los diputados locales, la mayoría consideró que se puede asegurar una mejor representación cuando se proporcionan bienes o servicios para los ciudadanos o cuando se comparten ideas políticas con estos.

Los estados cuyos diputados respondieron que se aseguraba una mejor representación a través de proporcionar bienes y servicios fueron sobre todo el Estado de México (78\%), Guerrero (70\%), Jalisco (54\%) y Nayarit (44\%) -de los rangos 4, 2 y 1-. Guanajuato y Tamaulipas -del rango 3- fueron los estados donde en el mismo sentido respondió sólo el $38 \%$ y $20 \%$ de los diputados, respectivamente, esto 
por debajo de la noción de representación como compartición de ideología. Entonces, la representación sustantiva (Pitkin, 1985) cobra sentido al entenderla como una actuación en nombre del representado, que se traduce en acciones y políticas públicas que resultan de la actividad del representante, más allá de la semejanza entre ambos, o incluso de sus posturas políticas. Entonces, el mecanismo de representación como espejo en términos territoriales sobre el que está basado el sistema electoral mexicano es poco importante para quienes ejercen la representación.

Algo que debe quedar claro es que en la política mexicana la dación de bienes y servicios no implica la noción de clientelismo que se encuentra en otros estudios. Después de revisar los estudios sobre este tema, se concluye que el clientelismo es un fenómeno más complejo, pero que no aplica a la realidad de las respuestas que otorgaron los legisladores entrevistados, pues mientras el clientelismo tiene la noción negativa de intercambio de bienes y servicios a cambio de apoyo electoral, los diputados locales hacían referencia a un fenómeno más bien de entrega de ayudas económicas a las personas necesitadas que se acercaron a sus oficinas. Incluso en el último Informe legislativo 2019, del Instituto Mexicano para la Competitividad (2019), se hace evidente este fenómeno, en que los Congresos locales cada vez gastan más presupuesto en ayudas sociales, es decir, asignaciones económicas a personas e instituciones de forma discrecional y sin reglas de operación.

En el mismo tenor, en la verbalización de los mismos entrevistados, se hacía notar la costumbre que tienen muchos de los ciudadanos de buscar a sus diputados para que les ayuden a gestionar trámites de Gobierno como infracciones de tránsito, problemas de gestión ante otras autoridades e incluso apoyos personales ante dificultades financieras. Estos resultados, sin duda, pueden dar pie a otros estudios comparados donde se pueda profundizar en 
¿Qué (no) representan los diputados locales? Sistema electoral mexicano, actitudes y desconfianza

los mecanismos causales detrás de cada realidad política subnacional.

Figura 5. Desde su función legislativa, ¿actúa de acuerdo a lo que sus votantes le piden o según lo que usted cree que es mejor para ellos?

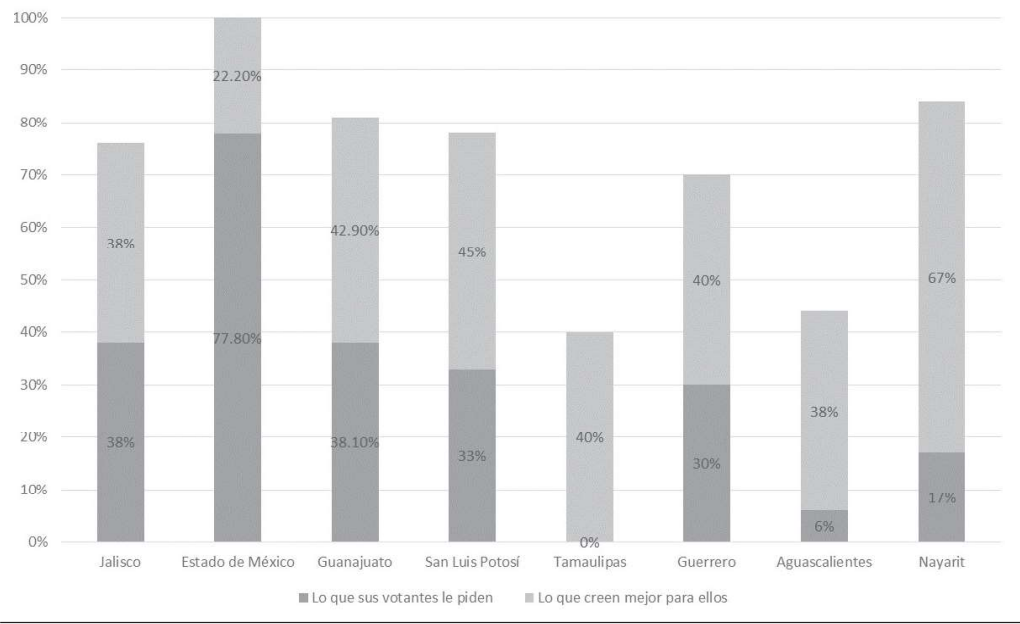

Número de casos: Aguascalientes $\mathrm{n}=27$, Nayarit $\mathrm{n}=15$, Sinaloa $\mathrm{n}=33$, Guerrero $n=10$, Guanajuato $n=21$, Tamaulipas $n=15$, San Luis Potosí $\mathrm{n}=13$, Estado de México n=9, Jalisco n=13. Se excluyó a Sinaloa, que no contaba con los resultados de esta pregunta, pero se conservó a Guerrero, otro estado de su mismo rango (2). Algunos porcentajes presentados no suman el $100 \%$ porque no se incluye en la figura la opción de respuesta "otra", planteada en la encuesta original.

Fuente: elaboración propia con base en Montaño y Patrón (2017).

La noción de representación delegativa o de fiduciario también ha sido un debate muy importante en la literatura respecto al rol que debe tener un legislador, sobre todo en un contexto donde la reelección legislativa inmediata no estaba permitida (hasta 2016). Con excepción del Estado de México y un empate en Jalisco, la mayoría de los diputados locales se concibe como un fiduciario o albacea de sus representados, es decir, los diputados creen que en su 
función legislativa deben actuar según lo que consideran mejor para ellos (Figura 5).

Figura 6. Entre los siguientes grupos, personas o instituciones, ¿a quién tiene más en cuenta cuando toma decisiones políticas en primer lugar?

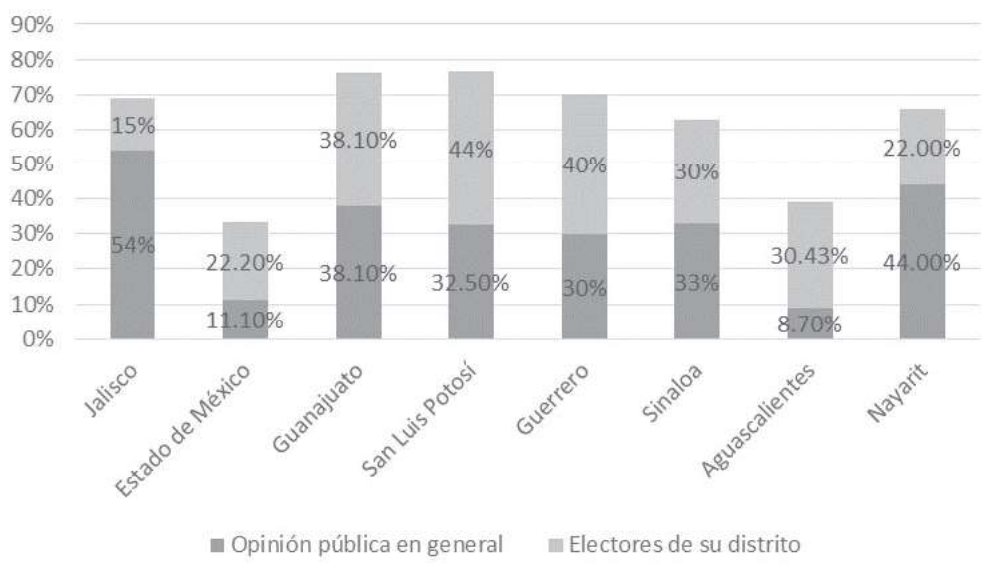

Número de casos: Aguascalientes $\mathrm{n}=27$, Nayarit $\mathrm{n}=15$, Sinaloa $\mathrm{n}=33$, Guerrero $n=10$, Guanajuato $n=21$, San Luis Potosí n=13, Estado de México $\mathrm{n}=9$, Jalisco $\mathrm{n}=13$. Se excluyó a Tamaulipas, que no contaba con los resultados de esta pregunta, pero se conservó a Guanajuato y San Luis Potosí como otros estados de su mismo rango (3).

Fuente: elaboración propia con base en Montaño y Patrón (2017).

Por otra parte, en la pregunta graficada en la Figura 6, se puede observar cómo la distancia entre la vida política del ciudadano en el distrito y la misma en el Congreso es cada vez mayor, esto evidenciado cuando se les pregunta a los diputados sobre sus influencias principales al tomar decisiones políticas. La Figura 6 refleja los mayores porcentajes de respuestas: la opinión pública en general y los electores del distrito. 
¿Qué (no) representan los diputados locales? Sistema electoral mexicano, actitudes y desconfianza

Es interesante que los dos estados que toman en cuenta a la opinión pública por encima de los electores del distrito son de los rangos extremos, como Nayarit con menor población representada por diputado local, y Jalisco con mayor población representada por diputado local. En estos estados, el $54 \%$ y $44 \%$ de los entrevistados, respectivamente, manifestó tomar más en cuenta a la opinión pública que a sus electores de distrito. El Estado de México, San Luis Potosí, Guerrero y Aguascalientes -del rango 4, 3, 2 y 1, respectivamente- fueron los estados donde la mayoría de sus diputados respondió tomar más en cuenta a los electores de su distrito con $22.2 \%, 44 \%$, $40 \%$ y $30 \%$, respectivamente. Sólo en Guanajuato los diputados contestaron exactamente por la mitad a cada una de las posturas.

En las entrevistas realizadas, los argumentos dados al respecto por los representantes versaban sobre todo sobre que la opinión pública suele ser muy importante para decidir en temas de trascendencia política y social, mientras que la mayoría de los diputados locales recibe numerosas llamadas y visitas de los habitantes de sus distritos para asuntos de gestión. Los entrevistados concordaron que al llegar al Congreso se deben tomar decisiones que involucran a todos, y que las decisiones dependen de las personas que en su distrito tienen mayor o menor influencia. Aunque en la Figura 6 no se incluyeron las respuestas con los porcentajes menores, es necesario decir que estas se referían a que las decisiones dependen de con quiénes se discuten (líderes políticos locales y nacionales, así como grupos de interés dominantes).

Estado No.77 
Tabla 7. Noción de representación de los diputados locales

\begin{tabular}{ccc}
$\begin{array}{c}\text { Representación } \\
\text { política que favorece }\end{array}$ & $\begin{array}{c}\text { Territorio que } \\
\text { representa }\end{array}$ & $\begin{array}{c}\text { Intereses que cree } \\
\text { representar }\end{array}$ \\
\hline $\begin{array}{c}\text { Sustantiva } \\
\text { fiduciaria }\end{array}$ & Todo el estado & Opinión pública en \\
& & general \\
\hline
\end{tabular}

Fuente: elaboración propia.

En cuanto a la noción de representación que poseen los legisladores locales entrevistados (Tabla 7), en general se encuentra muy alejada del arreglo institucional diseñado en el sistema electoral mexicano para tal fin, pues resaltan la representación sustantiva (Pitkin, 1967) y la fiduciaria (Burke, 1942a y 1942b; Eulau et al., 1959; Conniff, 1977; Cotta, 2007).

Además de las respuestas en sentido estricto que se muestran como resultado de la encuesta, en la charla con los legisladores fueron evidentes algunas referencias en torno a su papel en la representación. En ese sentido, algunos diputados entrevistados mencionaban que la mayoría de las demandas que recibían de los ciudadanos tenían que ver con solicitudes de índole personal, como ya se mencionaba, en concreto de solicitudes de apoyo económico para cubrir necesidades básicas.

Por otro lado, la sociedad civil organizada, los grupos de interés y los líderes de partidos políticos eran los actores con quienes se discutían sobre todo decisiones en torno al presupuesto público, al diseño de algunas iniciativas de ley o a temas de relevancia para la sociedad civil.

En el siguiente apartado, se comparan los niveles de confianza hacia los diputados locales por parte de los ciudadanos y la confianza hacia el propio Congreso local por parte de los legisladores entrevistados. Se puede adelantar que a pesar de que el trabajo legislativo dentro de los recintos aparentaba intensa actividad y mucha disposición de 
¿Qué (no) representan los diputados locales? Sistema electoral mexicano, actitudes y desconfianza

unos cuantos diputados locales, entre la opinión pública la desconfianza hacia el órgano legislativo crece.

\section{La crisis de representatividad de los diputados} y Congresos locales

La crisis de representatividad se ha estudiado en términos de desconfianza hacia los representantes o instituciones representativas, es decir, como una evaluación de estos. A partir de la internización de los fenómenos políticos (Almond y Verba, 1963; Easton, 1975), los ciudadanos son capaces de evaluar a actores o figuras del sistema político y expresar su nivel de aceptación o rechazo, expresado en términos de confianza (Easton, 1975; Montero, Zmerli, y Newton, 2008; Joignant, Morales, y Fuentes, 2017). En este sentido, lo que hacen o dejan de hacer los representantes incide en la confianza que los ciudadanos tienen hacia la institución de la que forman parte, por ejemplo, por la forma en que se relacionan con sus electores.

Así pues, el objetivo de este apartado es comparar la actitud de confianza por parte de los ciudadanos hacia los diputados (con base en datos de la encuesta de Instituto Nacional Electoral y El Colegio de México -2015-) ${ }^{19}$ y la confianza de los diputados hacia los propios Congresos locales (con base en la encuesta del Observatorio Político Electoral -2013-) para contribuir al debate sobre la crisis de representatividad que existe a nivel subnacional.

La evaluación de un diputado por parte de un ciudadano puede ser suficiente para evaluar a toda la institución y determinar su confianza (Butler, Karpowitz, y Pope, 2017). Por otra parte, los diputados son quienes interactúan directamente con otros diputados y con la estructura de la

19. Los únicos estados representativos estadísticamente en la encuesta y que forman parte de este estudio fueron Aguascalientes, Guanajuato y Estado de México. Los datos de los demás estados deben tomarse sólo como referencia. 
institución, por lo que son capaces de evaluar la institución en la que se desenvuelven.

A este respecto, ha habido pocos estudios en relación a la confianza de las élites en las instituciones. Algunos se han enfocado en la comparación del público más informado contra el público en general, como el Trust Barometer de Edelman (2019), y recientemente, con la base de datos del proyecto Élites Latinoamericanas (PELA), se están comenzando a explorar las causas de la confianza de las élites en las instituciones (Alcántara, s/f; Rivas y Alcántara, 2019).

En este apartado, se muestran los resultados comparados - de los estados según el rango de población representada por diputado local- de las respuestas de los ciudadanos a la pregunta: “¿qué nivel de confianza le merecen los diputados?", y de los diputados a la pregunta: “¿qué nivel de confianza le merece su Congreso local?". El resultado de ambas encuestas puede ser visualizado utilizando la misma escala (nada, poco, algo y mucha confianza).

$\mathrm{Al}$ iniciar con el estudio de los estados del rango 1, sería lógico pensar que una menor población representada entre 39164 y 92690 habitantes- facilitaría al diputado local la actividad de representación y de contacto con sus ciudadanos, por lo que podría hacerla mejor. Sin embargo, en la Figura 7 se puede apreciar que a pesar de tener a los diputados locales que representan menor población, la mayoría de los ciudadanos de Aguascalientes confía nada o poco en sus representantes ( $57 \%$ y $20 \%$, respectivamente); en Nayarit, dichas respuestas tienen porcentajes de $10 \%$ y $60 \%$, también respectivamente. 
¿Qué (no) representan los diputados locales? Sistema electoral mexicano, actitudes y desconfianza

Figura 7. Confianza legislativa de ciudadanos $y$ diputados locales. Estados de rango 1

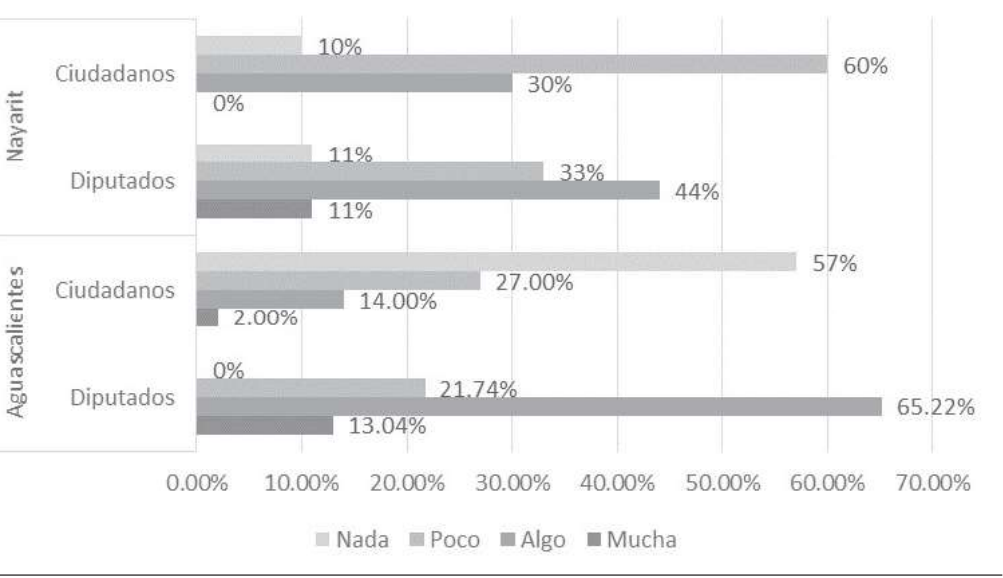

Se muestran los porcentajes de las respuestas de los ciudadanos a la pregunta ¿qué nivel de confianza le merecen los diputados?, y de los diputados a la pregunta ¿qué nivel de confianza le merece su Congreso local?

Fuente: elaboración propia con base en Montaño y Patrón (2017) y en Instituto Nacional Electoral y El Colegio de México (2015).

Como se verá en los siguientes casos, comienza a ser evidente que la tendencia es que son los diputados, y no los ciudadanos, quienes más confían en la institución legislativa: en Nayarit, el $44 \%$ de los diputados dijo confiar algo en la propia institución, y el 11\% mucho. Por otro lado, en Aguascalientes el $65 \%$ confía algo y el $13 \%$ mucho. 
Figura 8. Confianza legislativa de ciudadanos

$y$ diputados locales. Estados de rango 2

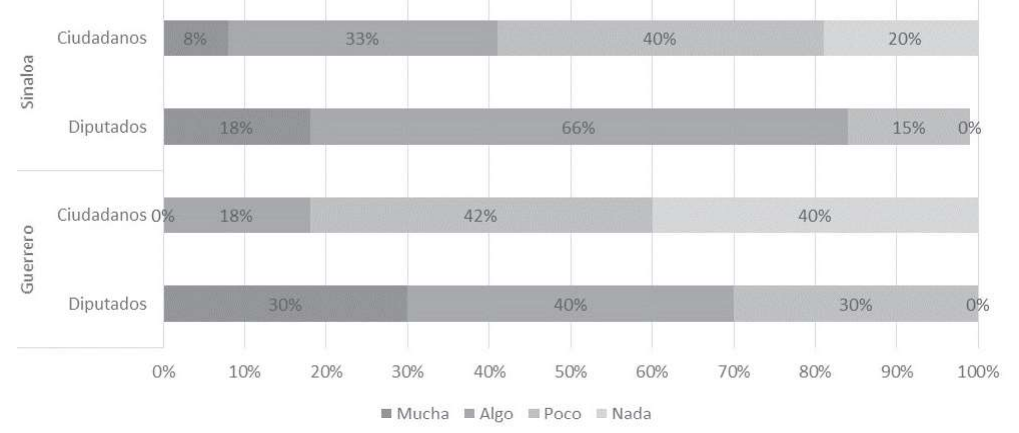

Se muestran los porcentajes de las respuestas de los ciudadanos a la pregunta ¿qué nivel de confianza le merecen los diputados?, y de los diputados a la pregunta ¿qué nivel de confianza le merece su Congreso local?

Fuente: elaboración propia con base en Montaño y Patrón (2017) y en Instituto Nacional Electoral y El Colegio de México (2015).

Por otro lado, entre los estados del rango 2, Sinaloa y Guerrero tienen a los diputados locales de mayoría relativa que representan a entre 92691 y 146217 ciudadanos. Mientras el $20 \%$ de los sinaloenses confía poco y $40 \%$ nada, en Guerrero el $42 \%$ confía poco y $40 \%$ no confía nada en sus diputados. Ahora bien, los diputados opinan lo contrario, y confían algo o mucho en el Congreso de Sinaloa (18\% y 66\%, respectivamente), del mismo modo que los diputados confían en su Congreso en Guerrero (30\% y 40\%, respectivamente) (Figura 8). Entonces, a pesar de que estas entidades tienen niveles de menor cantidad de ciudadanos representados por diputado de mayoría relativa, la crisis de representatividad en ellas es evidente. 
¿Qué (no) representan los diputados locales? Sistema electoral mexicano, actitudes y desconfianza

Figura 9. Confianza legislativa de ciudadanos y diputados locales. Estados de rango 3

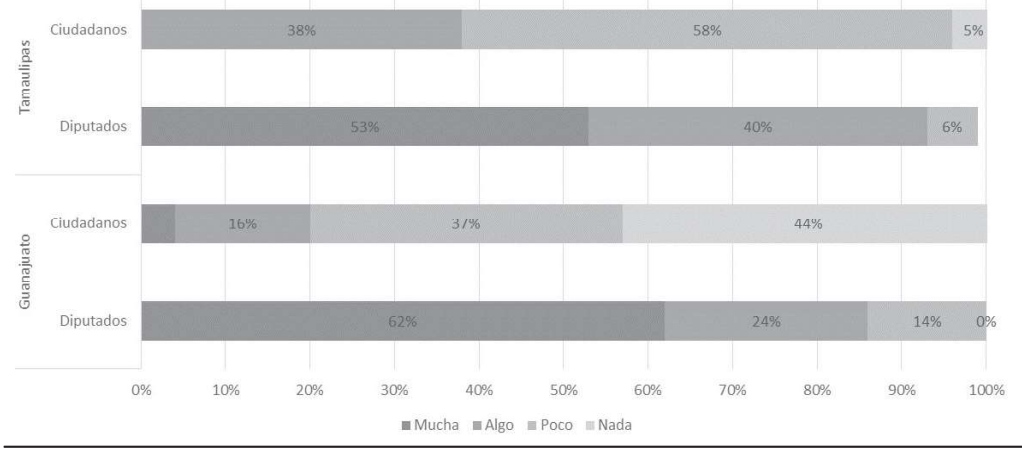

Se muestran los porcentajes de las respuestas de los ciudadanos a la pregunta ¿qué nivel de confianza le merecen los diputados?, y de los diputados a la pregunta ¿qué nivel de confianza le merece su Congreso local?

Fuente: elaboración propia con base en Montaño y Patrón (2017) y en Instituto Nacional Electoral y El Colegio de México (2015).

Por su parte, los estados de Guanajuato y Tamaulipas pertenecen al rango 3, es decir, en el que están diputados de mayoría relativa que representan a una población entre 146218 y 256534 habitantes. La desconfianza total no es muy distinta en ambos casos, pues mientras que en Guanajuato la mayoría de los ciudadanos (44\%) confía nada en su Congreso y $37 \%$ confía poco, en Tamaulipas el $5 \%$ confía nada y el 58\% confía poco (Figura 9 ).

De manera opuesta, los diputados locales en ambos estados confían algo o mucho en su Congreso. En Tamaulipas, alcanzan el $40 \%$ los diputados que dicen confiar algo y el $53 \%$ los que dicen confiar mucho en el órgano legislativo local, mientras que en Guanajuato llegan al 24\% la respuesta algo y $62 \%$ la respuesta mucho. Dichas respuestas muestran la gran brecha de confianza política que impera 
entre la clase política y los ciudadanos respecto del espacio legislativo.

Figura 10. Confianza legislativa de ciudadanos y diputados locales. Estados de rango 4

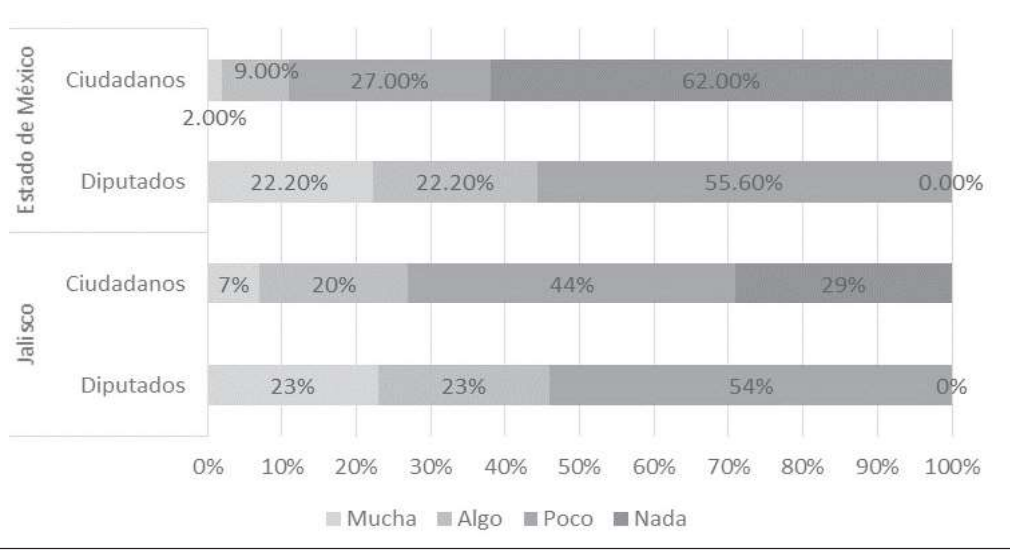

Se muestran los porcentajes de las respuestas de los ciudadanos a la pregunta ¿qué nivel de confianza le merecen los diputados?, y de los diputados a la pregunta ¿qué nivel de confianza le merece su Congreso local?

Fuente: elaboración propia con base en Montaño y Patrón (2017) y en Instituto Nacional Electoral y El Colegio de México (2015).

Finalmente, se analiza a los estados de Jalisco y Estado de México, que pertenecen al rango 4, con una población representada por diputado local de entre 256535 y 367534 habitantes. Se puede observar que los ciudadanos en general en ambos estados confían poco o nada en sus diputados. En el Estado de México, la mayoría confía nada (62\%) y poco (27\%), mientras que en Jalisco un $29 \%$ confía nada y un $44 \%$ poco. Esto contrasta con la posición de diputados en ambos estados, pues ninguno mencionó confiar nada en el Congreso local, aunque tanto Jalisco como el Estado de México tienen los porcentajes más altos de los diputados que confían poco 
¿Qué (no) representan los diputados locales? Sistema electoral mexicano, actitudes y desconfianza

en la institución, con $54 \%$ y $55.6 \%$, respectivamente. Los diputados de Jalisco confían de manera casi idéntica algo (23\%) o mucho (23\%) en su Congreso, así como los mexiquenses, con $22.2 \%$ de algo y $22.2 \%$ de mucho (Figura 10 ).

Tabla 8. Evaluación de los ciudadanos

y diputados a la actividad representativa

\begin{tabular}{cc}
$\begin{array}{c}\text { Nivel de confianza hacia los } \\
\text { diputados (ciudadanos) }\end{array}$ & $\begin{array}{c}\text { Niveles de confianza hacia los } \\
\text { Congresos locales (diputados) }\end{array}$ \\
\hline Poca o nula & Algo o mucha \\
\hline
\end{tabular}

Fuente: elaboración propia.

Esta crisis de representación que es observada en la desconfianza de los ciudadanos hacia los diputados da cuenta de que es necesario revisar el diseño institucional sobre el cual se ha basado la conformación de los espacios legislativos. Si una institución es valorada de manera totalmente opuesta entre quienes están inmersos en ella y quienes deberían ser el eje central de la actuación de la misma (Tabla 8), entonces existe un grave problema.

Además, se ha podido observar que no hay grandes diferencias en torno a opinión de la representación legislativa entre la población de los estados con los rangos de mayor cantidad de ciudadanos representada por diputado local y la de aquellos que tienen población menor en los distritos representados.

\section{Conclusiones}

Aunque no es novedad que los ciudadanos y los políticos vivan en realidades diferentes, en este artículo se propuso un marco de análisis para valorar el nivel de representatividad entre los representantes legislativos y sus representados. A partir del estudio de caso a nivel subnacional, se 
revisó: 1) la noción de representación que predomina en la legislación electoral, 2) las prácticas u opiniones respecto a la representación de los diputados locales, y finalmente 3) la presencia o no de crisis de representatividad.

Sobre la noción de representatividad en el sistema electoral mexicano, a lo largo de este artículo se demostró que la misma, sobre la cual está diseñado de manera predominante el sistema electoral de los Congresos locales mexicanos, es la territorial, que favorece las reglas electorales tomando como referencia el número de población concentrada en un distrito.

Del mismo modo, se observó que los diputados locales de mayoría relativa de México, al ser figuras regidas por leyes electorales locales, no representan a la misma cantidad de ciudadanos, y que sus entidades se pueden dividir en cuatro rangos, obtenidos a partir de los extremos del promedio nacional. A partir de este hallazgo, se seleccionaron diputados pertenecientes a los estados de los diversos rangos con el propósito de encontrar diferencias y similitudes en cuanto a las percepciones de ciudadanos y diputados respecto al ejercicio de la representación política.

En cuanto a la noción o actitud de los representantes sobre la representación, emanada de los resultados de la encuesta utilizada para hacer el presente análisis (Montaño y Patrón, 2017), cabe resaltar las dificultades que se encontraron en las respuestas de los diputados locales para definir cómo y a quién representaban en su labor como legisladores, y que en muchas ocasiones la noción de territorio sobre la que está basado el sistema electoral no correspondía al ejercicio y la dinámica diaria de los recintos legislativos.

Si bien la mayoría de los diputados locales tiene una visión de la representación como fiduciaria en términos de Burke (Burke, 1942a y 1942b; Eulau et al., 1959; Conniff, 1977; Cotta, 2007), los representantes no conciben que las similitudes socio-demográficas aseguren una mejor representación entre ellos y los ciudadanos. A partir de las entrevistas, 
¿Qué (no) representan los diputados locales? Sistema electoral mexicano, actitudes y desconfianza

sobresale que la atención personal del legislador para resolver un problema del ciudadano es el mejor mecanismo que se ha encontrado para asegurar una mejor representación, así como la inversión en apoyos sociales. Como se mencionó antes, lo dicho no se trata de una gestión en términos clientelares. Lo más relevante es que el diputado local se reconoce a sí mismo como un gestor del ciudadano que acude a él ante la complejidad del sistema político.

Por otro lado, a pesar de que la mayoría de los diputados aseguraba recibir en un mes normal una gran cantidad de llamadas, mensajes y visitas de los ciudadanos, su capacidad de gestión es siempre reducida frente a la gran población que representa. Eso se vio reflejado en la comparación de los niveles de confianza hacia la figura parlamentaria por parte de los mismos representantes y de los ciudadanos.

Finalmente, sobre la crisis de representatividad, esta se midió con el indicador de confianza hacia los diputados. El resultado fue que a pesar de la congruencia del sistema electoral y de la tradición constitucional que ha llevado a los Congresos locales a definir de manera territorial la representación de los ciudadanos por los diputados, existe una crisis de representación hacia la figura del diputado, expresada en altos niveles de desconfianza hacia estos según la encuesta de Instituto Nacional Electoral y El Colegio de México (2015).

Mientras los diputados se enfrentan a la complejidad institucional de representar al mismo tiempo a los ciudadanos de su distrito, a los votantes de su partido político y a todos los habitantes de su estado, los ciudadanos sienten una gran desconfianza hacia la figura del diputado, a quien consideran como poco o nada confiable.

Por un lado, el ciudadano busca en su representante respuestas inmediatas e individuales sobre problemas de gestión pública, y ve al diputado como un gestor que le puede ayudar frente a la complejidad administrativa del Gobierno, pero por 
otro lado, la relación entre grupos de interés, sociedad civil organizada y diputados se vuelve compleja en un contexto de competencia política y tensión entre el Gobierno y la oposición, que sin duda encuentra su lugar en una institución como el Congreso. También, el grado de conocimiento sobre ciertos temas y la complejidad de la práctica parlamentaria condicionan el tipo y el nivel de los participantes que buscan influir o dialogar con sus diputados.

También, resulta importante profundizar en las actitudes, comportamientos y demandas que los ciudadanos buscan resolver en los diputados utilizando otros estudios de opinión que incluyan métodos como encuestas y grupos focales, pues los reactivos en encuestas y bases de datos como los aquí revisados en torno a la relación representante-representado son muy limitados, y más a nivel subnacional.

Por último, es importante resaltar que la literatura en torno al tema del diseño institucional y el concepto de representación y su medición en espacios legislativos ha ido por caminos distintos, separando casi siempre a la teoría política de las instituciones dedicadas al diseño del sistema electoral. A ese respecto, sería deseable que los argumentos politológicos tuvieran incidencia en el diseño de los sistemas electorales para que se pudiera transitar de una mera legislación pensada para el proceso electoral a un diseño que prevea los mecanismos subsecuentes a la obtención de los escaños en las legislaturas. En ese sentido, quizás el enfoque subnacional sea una oportunidad para mejorar desde los Congresos locales la calidad de la representación política, debido a que vuelve la esfera pública local un entorno más accesible para la población. 
¿Qué (no) representan los diputados locales? Sistema electoral mexicano, actitudes y desconfianza

Aguiar, A. A., y Macedonio, M. O. (20I7). Democracia y representación en el Poder Legislativo de Nayarit. En M. Montaño, y F. Patrón (Coords.), Élites parlamentarias locales en México: actitudes y desempeño (pp. 195-220). México:Tirant lo Blanch.

Alcántara, M. (Dir.) (s/f). Proyecto Élites Latinoamericanas (PELAUSAL). Recuperado de https://oir.org.es/pela/

Almond, G. A., y Verba, S. (1963). La cultura política. En AA.VV.,Diez textos básicos de ciencia política (pp. I7I-20I). México:Ariel.

BritoVieira, M.,y Runciman, D. (2008). Representation. Malden: Polity Press.

Butler, D. M., Karpowitz, C., y Pope, J. (2017). Who Gets the Credit? Legislative Responsiveness and Evaluations of Members, Parties, and the us Congress. Political Science Research and Methods, 5(2), 35I-366.

Burke, E. (1942a). Discurso a los electores de Bristol. En E. Burke (Aut.), Textos políticos (pp. 309-3 I 5). México: Fondo de Cultura Económica.

Burke, E. (1942b). Reflexiones sobre la revolución francesa. En E. Burke (Aut.), Textos políticos (p. 39). México: Fondo de Cultura Económica.

Casas, E. (2017). Percepciones de los diputados tamaulipecos sobre la democracia y las instituciones del estado. En M. Montaño, y F. Patrón (Coords.), Élites parlamentarias locales en México: actitudes y desempeño (PP. 67-90). México:Tirant lo Blanch.

Conniff, J. (1977). Burke, Bristol, and the Concept of Representation. The Western Political Quarterly, 30(3), 329-34I.

Cotta, M. (2007). Representación política. En AA.VV., Diccionario de ciencia política (PP. I 384- I 390). México: Siglo XXI.

Cox, G. (2004). La coordinación estratégica de los sistemas electorales del mundo. Barcelona: Gedisa.

Estado No.77 
Bibliografía $\quad$ De Grazia, A. (1977). Representación. En D. Sills (Coord.), Enciclopedia internacional de las ciencias sociales (p. 303). Madrid:Aguilar Ediciones.

Easton, D. (1975). A Re-assessment of the Concept of Political Support. British Journal of Political Science, 5(4), 435-457.

Edelman (2019). Trust Barometer Global Report. Recuperado de https://www.edelman.com/sites/g/files/aatuss I9 I/ files/2019-02/2019_Edelman_Trust_Barometer Global_Report.pdf

Enriquez, L. (2010). Confianza ciudadana en el Poder Legislativo. Congreso de la Unión mexicano. En A. Moreno (Ed.), La confianza en las instituciones. México en perspectiva comparada (PP. 147-174). México: CESOP.

Eulau, H.,Wahlke, J., Buchanan,W.,y Ferguson, C. (1959).The Role of the Representative: Some Empirical Observations on the Theory of Edmund Burke. American Political Science Review, 53(3), 742-756.

Hernández, N.E.(20I7). La élite parlamentaria y el "Gobierno del cambio" en Sinaloa (20 I0-20 I3). Opiniones, percepciones, valores y actitudes. En M. Montaño, y F. Patrón (Coords.), Élites parlamentarias locales en México:actitudes y desempeño (PP. I I5-138). México:Tirant lo Blanch.

Instituto Mexicano para la Competitividad (2017). Informe legislativo 2017. Recuperado de https://imco.org.mx/ competitividad/informe-legislativo-20I7/

Instituto Mexicano para la Competitividad (2019). Informe legislativo 2019. Recuperado de https://imco.org.mx/temas/ la-austeridad-sigue-sin-llegar-a-los-congresos-locales/

Instituto Nacional de Estadística y Geografía (2016). Información geoelectoral y acuerdos. Estadísticas censales a escala geoelectoral. Recuperado de http://gaia.inegi.org. $\mathrm{mx/geoelectoral/viewer.html}$

Instituto Nacional Electoral (20 I 5). Acuerdo de la Junta General Ejecutiva del Instituto Nacional Electoral por el que se 
¿Qué (no) representan los diputados locales? Sistema electoral mexicano, actitudes y desconfianza

aprueba el plan de trabajo del proyecto de distritación para

Bibliografía las entidades federativas con procesos electorales locales 2015-2016 y 2016-2017 INE/JGE45/2015. Recuperado de https://portalanterior.ine.mx/archivos3/portal/historico/ contenido/interiores/Menu_Principal-id-Mesas_Distritaciones_Electorales/

Instituto Nacional Electoral,y El Colegio de México (20I5). Informe país de la calidad de la ciudadanía en México. México: Instituto Nacional Electoral. Recuperado de https://portalanterior.ine.mx/archivos2/portal/DECEYEC/EducacionCivica/informePais/

Jiménez, B. M.,y Solano, R. G. (2017). Perfil político profesional de los legisladores en el Congreso de Guerrero. En M. Montaño, y F. Patrón (Coords.), Élites parlamentarias locales en México: actitudes y desempeño (pp. 277-312). México:Tirant lo Blanch.

Joignant, A., Morales, M., y Fuentes, C. (2017). Malaise in representation in Latin American countries. Estados Unidos: Palgrave Macmillan.

Junta Nacional Instuyente del Imperio de Iturbide (I822). Reglamento político provisional político del Imperio Mexicano. Recuperado de http://museodelasconstituciones.unam. $\mathrm{mx} /$ nuevaweb/wp-content/uploads/2019/02/Reglamento-poli\%CC\%8I tico-del-Gobierno-del-Imperio-Mexicano- I822.pdf

Körösényi, A. (2009). Beyond the Happy Consensus about Democratic Elitism. Comparative Sociology, (8), 364-382. Laporta, F. (s/f). Sobre la teoría de la democracia y el concepto de representación política: algunas propuestas para debate. Recuperado de https://rua.ua.es/dspace/bitstream// 0045// 0839///Doxa6_06.pdf

Lujambio,A. (1996). Gobiernos divididos en la federación mexicana. México: UAM/IFE. 
Bibliografía $\quad$ Macedonio, M. O., y Montaño, R. M. (2018). La aritmética de la representación política: análisis de 31 estados. México: Instituto Electoral del Estado de México.

Miller, W., y Stokes, D. (1963). Constituency Influence in Congress. The American Political Science Review, 57(I), 45-56. doi https://doi.org//0.2307//9527/7

Montaño, M., y Patrón, F. (Coords.) (2017). Élites parlamentarias locales en México: actitudes y desempeño. México: Tirant lo Blanch.

Montero, J. R., Zmerli, S., y Newton, K. (2008). Confianza social, confianza política y satisfacción con la democracia. Revista española de investigaciones sociológicas, I 22, I I-54.

Morgan, R. (1974). Madison's Theory of Representation in the Tenth Federalist. The Journal of Politics, 36(4), 852-885.

Muñoz, A. A., y Díaz, J. O. (2017). Los límites del control parlamentario en el nivel subnacional en un contexto de democratización política: el caso del Estado de México. En M. Montaño, y F. Patrón (Coords.), Élites parlamentarias locales en México: actitudes y desempeño (pp. 17I-194). México:Tirant lo Blanch.

Observatorio Político Electoral (2013). Encuesta Élites Parlamentarias Locales en México. Recuperado de https:// bit.ly/2n5Pyw I

Pasquino, G. (20I I). Nuevo curso de ciencia política. México: Fondo de Cultura Económica.

Pitkin, H. (1967). The concept of representation. Estados Unidos: University of California Press.

Pitkin, H. ( 1985). El concepto de representación. Madrid: Centro de Estudios Constitucionales.

Putnam, R. (1973). Beliefs of politicians: ideology, conflict and democracy in Britain and Italy. Estados Unidos: Conn.

Rehfeld, A. (2005). The Concept of Constituency: Political Representation, Democratic Legitimacy and Institutional Design. Cambridge: Cambridge University Press. 
¿Qué (no) representan los diputados locales? Sistema electoral mexicano, actitudes y desconfianza

Rehfeld, A. (2018). On Representing. The Journal of Political

Bibliografía Philosophy, 26(2), 216-239.

Reyes, R. A. (20I7). Congreso local en Aguascalientes, cambio y continuidad. En M.Montaño,y F. Patrón (Coords.), Élites parlamentarias locales en México: actitudes y desempeño (pp. 139-170). México:Tirant lo Blanch

Reynolds, A., Reilly, B., y Ellis, A. (2005). Electoral System Design:The New International IDEA Handbook. Estocolmo: International IDEA Institute for Democracy and Electoral Assistance. Recuperado de https://www.idea.int/publications/catalogue/electoral-system-design-new-international-idea-handbook

Rivas, C.,yAlcántara, M. (2019). Confianza política de la élite parlamentaria en América Latina [ponencia presentada en el $x$ Congreso Latinoamericano de Ciencia Política]. Asociación Latinoamericana de Ciencia Política:México.

Sartori, G. (1988). Teoría de la democracia. Parte l: el debate contemporáneo. Madrid: Alianza Editorial.

Sistema de Información Legislativa (2017). Distrito electoral. Glosario en línea de la Secretaría de Gobernación. Recuperado de http://sil.gobernacion.gob.mx/Glosario/ glosario.php

Solís, D. J. M., Cerna, V. S., y Torre, D.V. (2017). La élite y su caparazón: la impenetrabilidad de los diputados locales de San Luis Potosí 20 I2-20I5. En M. Montaño,y F. Patrón (Coords.), Élites parlamentarias locales en México:actitudes y desempeño (Pp. 9I-II4). México:Tirant lo Blanch.

Stokes, S. (1998). Constituency influence and representation. Electoral studies, I 7(3), 35I-367.

Vallés, J. M., y Bosch,A. (1997). Sistemas electorales y gobierno representativo. Barcelona:Ariel.

Vázquez, F. C., Díaz, J. O., y Hernández, G. A. (2017). Los legisladores del estado de Guanajuato: una aproximación a su concepción sobre las funciones de producción legislativa, control político y representación. En M. Mon- 
Mónica Montaño Reyes

$$
\bullet \bullet
$$

Bibliografía taño, y F. Patrón (Coords.), Élites parlamentarias locales en México: actitudes y desempeño (pp. 247-276). México: Tirant lo Blanch. 